\title{
Clinical Study on Different Delivery Methods of Twin Pregnancy
}

\author{
Liyan $\mathrm{Hu}, \mathrm{MD}^{1}$ (1) \\ ${ }^{1}$ Department of Obstetrics and Gynaecology, Children's Hospital of \\ Shanxi, Women Health Center of Shanxi, Taiyuan City, Shanxi \\ Province, PR China \\ Am J Perinatol
}

Address for correspondence Liyan Hu, MD, Department of Obstetrics and Gynaecology, Women Health Center of Shanxi, Children's Hospital of Shanxi, Taiyuan City, Shanxi Province, PR China, Building 3, Lishui Yuan, Nantun, Wanlin District, Taiyuan 030013, Shanxi, China (e-mail: LiyanHudr@163.com).

\begin{abstract}
Keywords

- twin pregnancy

- delivery methods

- pregnancy outcomes

Objective To investigate the effect of different methods of delivery on the outcome of twin pregnancies.

Methods This is a retrospective cohort review of 627 twin pregnancies with delivery from January 2016 to December 2019. According to the clinical guidelines for cesarean section, the cesarean section and vaginal delivery groups were determined. Finally, the baseline information, delivery method, pregnancy outcome, and maternal and infant complications of the two groups were compared.

Results For different delivery methods, the incidence of preeclampsia was significantly higher in the cesarean section group than in the vaginal delivery group $\left(x^{2}=4.405, p<0.05\right)$. There were 23 fetal growth ratios (FGR) in the cesarean section group, which were significantly higher than the vaginal delivery group $\left(x^{2}=4.740\right.$, $p<0.05)$. However, the incidence of preterm premature rupture of membranes (PPROM) in the vaginal delivery group was significantly higher than in the cesarean section group $\left(X^{2}=5.235, p<0.05\right)$. In addition, the volume of postpartum bleeding in the vaginal delivery group was significantly higher than in the cesarean section group $(t=4.723, p<0.001)$. The neonatal weights and 5 -minute Apgar scores of the vaginal delivery group were lower than the cesarean section group, and the difference was statistically significant. In the vaginal delivery group, 48 and 26 neonates were transferred to the intensive care and neonatal units, respectively, which were significantly higher than in the cesarean section group $\left(x^{2}=5.001, p<0.05\right)$.

Conclusion The major complications of a twin pregnancy are gestational diabetes mellitus and PPROM. Cesarean section can reduce the rate of neonatal asphyxia in twins and improve the pregnancy outcome.
\end{abstract}

With the continuous development of new assisted reproductive technologies, the incidence of twin pregnancies is increasing yearly. Twin pregnancies are high-risk, which increases the probability of gestational hypertension, gestational diabetes, and premature rupture of membranes (PROM). Adverse preg-

received

April 29, 2021

accepted after revision

July 19, 2021
DOI https://doi.org/

$10.1055 / \mathrm{s}-0041-1735492$.

ISSN 0735-1631. nancy outcomes, such as premature birth, twin transfusion syndrome, fetal malformations, neonatal asphyxia, neonatal pneumonia, etc., are prone to occur. ${ }^{1}$ The risk in the process of delivery is significantly higher than in single pregnancies, and umbilical cord prolapse, placental abruption, fetal distress, (c) 2021. The Author(s).

This is an open access article published by Thieme under the terms of the Creative Commons Attribution-NonDerivative-NonCommercial-License, permitting copying and reproduction so long as the original work is given appropriate credit. Contents may not be used for commercial purposes, or adapted, remixed, transformed or built upon. (https://creativecommons.org/ licenses/by-nc-nd/4.0/)

Thieme Medical Publishers, Inc., 333 Seventh Avenue, 18th Floor, New York, NY 10001, USA 
Key Points

- Twin pregnancy

- Delivery methods

- Pregnancy outcomes

abnormal fetal position, and conversion to cesarean section are more likely to occur. Choosing a reasonable delivery method, effectively improving the outcome of twin pregnancies, and reducing maternal and infant complications should be comprehensively evaluated and considered by clinicians. ${ }^{2,3}$ This article conducted a clinical study on the factors affecting the selection of delivery methods for 627 twin pregnancies admitted to our hospital from January 2016 to December 2019.

\section{Materials and Methods}

\section{General Data}

Six hundred twenty-seven cases of pregnant women carrying twins at our hospital from January 2016 to December 2019 were selected as the research subjects. According to different delivery methods, the pregnant women having twins were divided into the vaginal delivery (104 cases) and the cesarean section groups (523 cases).

\section{Methods}

The general baseline data, including age, gestational week, parity, and conception method of the two groups, were retrospectively analyzed. The clinical data, pregnancy complications, and maternal and infant outcomes between the two groups were compared, including blood loss, the time between deliveries, postpartum hemorrhage, pregnancy complications, neonatal outcome, etc.

\section{Choice of Delivery Method}

Any choice of delivery method should be based on the informed consent of pregnant women and their families, and obstetricians should fully communicate the risks and benefits of different delivery methods. The choice of delivery method is mainly determined by comprehensive evaluation of the chorion, fetal position, pregnancy complications, pregnancy history, intrauterine fetal condition, and the capability of neonatal treatment.

\section{Indications for Cesarean Section}

When the first fetus is in a non-cephalic presentation, umbilical cord prolapse and fetal delivery difficulty occur easily. At the same time, if the second fetus is in cephalic presentation, fetal head locking may occur. Cesarean section can reduce neonatal mortality. ${ }^{3}$ As for the delivery method for MCMA, the guidelines of China, France, and the United States pointed out that an MCMA twin pregnancy is an indication for cesarean section. ${ }^{4-6}$

\section{Indications for Vaginal Delivery}

For uncomplicated DCDA and MCDA twin pregnancies, if the first fetus is in cephalic presentation, regardless of the fetal position of the second fetus, vaginal delivery can be considered when the pregnant woman fully understands the risk and gives informed consent. ${ }^{7}$

\section{Statistical Processing}

SPSS 22.0 software was used for analysis, and the normal distribution measurement data were expressed as mean \pm standard deviation $(\overline{\mathrm{x}} \pm \mathrm{SD})$. A t-test was used for comparison between the two groups, and ANOVA was used for multiple group comparison. The count data within or between two groups were expressed as a percent (\%), and the chi-square $\left(X^{2}\right)$ test was used. $p<0.05$ indicates that the difference was statistically significant.

\section{Results}

Comparison of the Baseline Data of Twin Pregnancies Comparing the baseline data of pregnant women with twins, the age of the vaginal delivery group was $29.21 \pm 0.36$ years old, the gestational week of delivery was $31.53 \pm 0.33$ weeks, and more than half $(58.65 \%)$ were multipara. The age of the cesarean section group was $30.34 \pm 0.17$ years old $(t=2.699$, $p=0.007$ ), the gestational age of delivery was $35.60 \pm 0.13$ weeks $(\mathrm{t}=12.614, p<0.05)$. Primiparas were the majority, and the difference was significant between the two groups. The proportion of test-tube babies in both groups was very high, but the difference was not significant. Therefore, the choice of delivery method for a twin pregnancy should be based on the maternal age, method of pregnancy, delivery history, gestational week, fetal size, and other factors ( - Table 1 ).

\begin{tabular}{|lllllll|}
\hline \multicolumn{7}{|l|}{ Table 1 Comparison of baseline data of twin pregnancy with different delivery modes } \\
\hline Groups & Cases & Age & Gestational Weeks & Primipara & Multipara & Test-tube Baby \\
Vaginal Delivery & 104 & $29.21 \pm 0.36$ & $31.53 \pm 0.33$ & $43(41.34)$ & $61(58.65)$ & $71(68.27)$ \\
Cesarean Sections & 523 & $30.34 \pm 0.17$ & $35.60 \pm 0.13$ & $391(74.76)$ & $132(25.24)$ & $396(75.72)$ \\
t Value & & 2.699 & 12.614 & & & \\
X2 & & & 6.310 & & 2.532 \\
P & & 0.007 & $<0.001$ & 0.001 & $<0.001$ & 0.073 \\
\hline
\end{tabular}

Note: Compared with the control group, $p<0.05$. 


\begin{tabular}{|c|c|c|c|c|c|c|c|}
\hline Groups & Cases & Gestational Diabetes & Preeclampsia & $\mathrm{SCH}$ & FGR & PPROM & $\begin{array}{l}\text { postpartum } \\
\text { bleeding volume }\end{array}$ \\
\hline Vaginal Delivery & 104 & $15(14.42)$ & $13(12.5)$ & $11(10.58)$ & $0(0)$ & $23(22.12)$ & $611.54 \pm 397.74$ \\
\hline \multirow[t]{3}{*}{ Cesarean Sections } & 523 & $84(16.06)$ & $62(11.85)$ & $55(10.52)$ & 23 (4.39) & $70(13.38)$ & $451.61 \pm 296.29$ \\
\hline & & 0.188 & 4.405 & 3.125 & 4.740 & 5.235 & 4.723 \\
\hline & & 0.665 & 0.036 & 0.077 & 0.021 & 0.022 & $<0.001$ \\
\hline
\end{tabular}

Note: Compared with the control group, $p<0.05$.

\section{Comparison of Complications in Twin Pregnancies with Different Delivery Methods}

The most common complications were gestational diabetes mellitus and preterm premature rupture of membranes (PPROM). Complications were compared between the two groups. The incidence of preeclampsia was significantly higher in the cesarean section group than in the vaginal delivery group $\left(X^{2}=4.405, p<0.05\right)$. There were 23 fetal growth ratios (FGR) in the cesarean section group, which were significantly higher than the vaginal delivery group $\left(X^{2}=4.740, p<0.05\right)$. However, the incidence of PPROM in the vaginal delivery group was significantly higher than in the cesarean section group $\left(x^{2}=5.235, p<0.05\right)$. In addition, the volume of postpartum bleeding in the vaginal delivery group was $611.54 \pm 397.74 \mathrm{ml}$ and was $451.61 \pm 296.29 \mathrm{ml}$ in the cesarean section group, and the difference was statistically significant $(t=4.723, p<0.001)$. However, gestational diabetes mellitus and subclinical hypothyroidism $(\mathrm{SCH})$ were not significantly different between the two groups (-Table 2).

\section{Comparison of Neonatal Conditions Between the Two Groups}

The neonatal weights and 5-minute Apgar scores of the vaginal delivery group were lower than those of the cesarean section group, and the difference was statistically significant. The vaginal delivery group had mostly premature delivery, and gestation was $\sim 32$ weeks, while most of the cesarean section group were close to full-term. In the vaginal delivery group, 48 and 26 neonates were transferred to the intensive care and neonatal units, respectively, which were significantly higher than in the cesarean section group $\left(X^{2}=5.001, p<0.05\right)$. However, there was no difference in the incidence of neonatal malformation between the two groups (- Tables 3 and 4 ).

\section{Discussion}

Twin pregnancies are high-risk and prone to complications, such as gestational diabetes mellitus, preeclampsia, and $\mathrm{SCH}$. When the condition is severe, it will seriously affect the safety of mothers and babies. To reduce the risk, timely termination of pregnancy is required. Cesarean section can shorten the labor process and reduce the incidence of fetal distress. Fetal distress, umbilical cord prolapse, placental abruption, abnormal fetal position, and transition to cesarean section may occur during vaginal delivery. Most primipara women believe that vaginal delivery is risky and painful, and cesarean section is relatively safe. Even though vaginal delivery has a high success rate, they tend to choose a cesarean section. The results of this study showed that the probability of cesarean section during pregnancy with preeclampsia is relatively increased, which is significantly different from the vaginal delivery group $\left(x^{2}=4.405, p<0.05\right) \cdot{ }^{8-10}$ Fetal growth restriction could not tolerate uterine contraction and was prone to fetal distress, so cesarean section was needed to terminate the pregnancy, which was significantly different from the vaginal delivery group $\left(\mathrm{X}^{2}=4.740, p<0.05\right)$. However, there was no significant difference between the cesarean section and the vaginal delivery groups with gestational diabetes and $\mathrm{SCH}$ $\left(X^{2}=0.188,3.125, P>0.05\right)$. The neonatal weight in the cesarean section group was higher than in the vaginal delivery group, and the difference was significant. $(t=14.245, p<0.001)$.

Even if there is no obstetric indication for cesarean section, older and IVF pregnant women will usually choose a cesarean section, which increases the cesarean section rate but reduces the incidence of neonatal asphyxia, neonatal transfer, and postpartum hemorrhage. The results of this study confirmed that there were significant differences in neonatal asphyxia between different delivery methods of twin pregnancy $(t=6.332, p<0.001)$. There was a significant difference in neonatal transport $\left(X^{2}=27.444, p<0.001\right)$.

\begin{tabular}{|lllll|}
\hline \multicolumn{4}{|l}{ Table 3 Comparison of perinatal outcomes of twin pregnancy with different delivery modes (n, \%) } \\
\hline Groups & Cases & Neonatal transferred to NICU & $\begin{array}{l}\text { Neonatal transferred } \\
\text { to neonatology }\end{array}$ & Neonatal Malformation \\
Vaginal Delivery & 104 & $48(46.15)$ & $26(25)$ & $6(5.77)$ \\
Cesarean Sections & 523 & $113(21.61)$ & $198(37.86)$ & $34(6.51)$ \\
X2 & & 5.001 & & 0.017 \\
P & & 0.025 & & 0.897 \\
\hline
\end{tabular}

Note: Compared with the control group, $p<0.05$. 


\begin{tabular}{|llllll|}
\hline \multicolumn{2}{|l}{ Table 4 Comparison of perinatal weight and Apgar score of twin pregnancy with different delivery modes } \\
\hline Groups & Cases & Neonatal Weight 1 & Apgar Score & Neonatal Weight 2 & $\begin{array}{l}\text { Apgar Score } \\
\mathbf{2}\end{array}$ \\
& & & 1 & & \\
Vaginal Delivery & 104 & $1633.62 \pm 575.98$ & $8.53 \pm 2.07$ & $1667 \pm 579.714$ & $8.79 \pm 2.058$ \\
Cesarean Sections & 523 & $2426.56 \pm 479.11$ & $9.60 \pm 1.30$ & $2353.44 \pm 505.18$ & $9.70 \pm 1.078$ \\
t Value & - & 11.805 & 6.541 & 14.245 & 6.332 \\
P & & $<0.001$ & $<0.001$ & $<0.001$ & $<0.001$ \\
\hline
\end{tabular}

Note: Compared with the control group, $p<0.05$.

There was a significant difference in neonatal weight $(\mathrm{t}=14.245, p<0.001)$.

The postpartum hemorrhage was $611.54 \pm 397.74 \mathrm{ml}$ in the vaginal delivery group and $451.61 \pm 296.29 \mathrm{ml}$ in the cesarean section group $(t=4.723, p<0.05)$, and the difference was significant. The vaginal delivery group was significantly higher than the cesarean section group, which is mainly related to twin pregnancies being prone to uterine atony. Vaginal delivery can only be given drug treatment. Cesarean sections cannot only be given drug treatment but also can be given a variety of means of suture hemostasis (such as lower uterine segment "8" suture, B-Lynch suture, uterine artery ligation), uterine cavity packing, and other means, and the measures are relatively increased, so the incidence of postpartum hemorrhage was reduced.

The most common complication of twin pregnancy is preterm delivery. The uterus of twin pregnant women in late pregnancy is overstretched, which leads to muscle fiber tension, cervical ripening, and premature delivery. Preterm birth is the most common cause of the fetal death of twins, especially for a fetus whose gestational age is less than 33 weeks, whose weight is low, and whose organs are immature. ${ }^{11}$ Premature delivery can easily cause severe complications, such as asphyxia and death. The results showed that the early preterm birth rate in the vaginal delivery group increased significantly, with gestation less than 34 weeks accounting for the majority, while the cesarean delivery group had gestation after 34 weeks $\left(X^{2}=201.453, p<0.05\right)$. The difference between the two groups was significant, which primarily depended on the treatment ability of different medical institutions for newborns, fetal survival rate, and the family economic status of pregnant women and their expectations for their newborns. For twin pregnancies in a small month, most families have high monetary expenses and poor financial abilities, so they may choose vaginal delivery. In cases such as IVF, the expectation for the newborn is high, and the probability of selecting a cesarean section will increase.

In conclusion, the major complications of twin pregnancies are gestational diabetes mellitus and PPROM. Cesarean section can reduce the rate of neonatal asphyxia in twins and improve the pregnancy outcome. Obstetricians should choose the delivery method scientifically according to the medical condition, the technical level of the staff, the condition of the pregnant woman and the fetus, and so on, to ensure safety. The most important principle is to reduce the asphyxia and mortality rates of perinatal infants.

\section{Declarations}

Ethics Approval and Consent to Participate

This study was conducted in accordance with the declaration of Helsinki. This study was conducted with approval from the Ethics Committee of Shanxi Wemen and Children Hospital. Written informed consent was obtained from all participants.

Ethics board approval number: IRB-KY-2019=002

\section{Consent for Publication}

Not applicable.

\section{Authors' Contributions}

Liyan Hu have made substantial contributions to conception and design, Liyan Hu acquisition of data, analysis and interpretation of data; Liyan $\mathrm{Hu}$ have been involved in drafting the manuscript and revising it critically for important intellectual content;Liyan Hu have given final approval of the version to be published.

\section{Availability of Data and Materials}

All data generated or analyzed during this study are included in this published article

\section{Funding}

This work was supported by Study on the influence of weight gain during pregnancy on glucose and lipid metabolism and perinatal outcome of twin pregnancy:201914

\section{Conflict of Interest}

None declared.

Acknowledgments

Not applicable.

\section{References}

1 Leetz I. Twin pregnancy as a high risk pregnancy: new medical statistical data from the German Democratic Republic. Acta Genet Med Gemellol (Roma) 1976;25:307-310. Doi: 10.1017/s0001566000014318

2 Feng B, Zhai J, Cai Y. Effect of twin pregnancy chorionic properties on maternal and fetal outcomes. Taiwan J Obstet Gynecol 2018;57 (03):351-354. Doi: 10.1016/j.tjog.2018.03.002 
3 Weiner E, Barber E, Feldstein O, et al. Placental Histopathology Differences and Neonatal Outcome in Dichorionic-Diamniotic as Compared to Monochorionic-Diamniotic Twin Pregnancies. Reprod Sci 2018;25 (07):1067-1072. Doi: 10.1177/1933719117732163

4 American College of Obstetricians and Gynecologists, Society for Maternal-Fetal Medicine. ACOG Practice Bulletin No. 144: Multifetal gestations: twin, triplet, and higher-order multifetal pregnancies. Obstet Gynecol 2014;123(05):1118-1132. Doi: 10.1097/01. AOG.0000446856.51061.3e

5 Vayssière C, Benoist G, Blondel B, et al; French College of Gynaecologists and Obstetricians. Twin pregnancies: guidelines for clinical practice from the French College of Gynaecologists and Obstetricians (CNGOF). Eur J Obstet Gynecol Reprod Biol 2011; 156(01):12-17. Doi: 10.1016/j.ejogrb.2010.12.045

6 Sun LM, Zhao YY, DuanT. Guidelines for clinical management of twin pregnancy (Part 1)-Monitoring and treatment of twin pregnancy during pregnancy.. [J/CD]Chin J Prenat Diag 2015;7(03):1-8. https:/| www.cnki.net/KCMS/detail/detail.aspx?filename=ZGCQ201503002\& dbname $=$ cjfdtotal\&dbcode $=C J F D \& V=$ MTQ2MDR6aFIVN3pzT1QzaVFyUmN6RnJDVVI3dWZiK1JxRmlEaFZyN01QeXJJZjdHNEg5VE1ySTIGWm9SNkRnOC8 $=$
7 Zhu YC, Sun Y, Yang HX. Evidence based medicine evidence for delivery timing and mode of twin pregnancy. Chinese. J Perinat Med 2015;18 (02):145-147. Doi: 10.3760/cma.j.issn.1007-9408.2015.02.015. http:// rs.yiigle.com/CN113903201502/65953.htm

8 Yamashita A, Ishii K, Taguchi T, et al. Adverse perinatal outcomes related to the delivery mode in women with monochorionic diamniotic twin pregnancies. J Perinat Med 2014;42(06): 769-775. Doi: 10.1515/jpm-2014-0072

9 Moussa HN, Leon MG, Marti A, et al. Pregnancy Outcomes in Women with Preeclampsia Superimposed on Chronic Hypertension with and without Severe Features. Am J Perinatol 2017;34 (04):403-408. Doi: 10.1055/s-0036-1592134

10 Moussa HN, Leon MG, Marti A, et al. Pregnancy Outcomes in Women with Preeclampsia Superimposed on Chronic Hypertension with and without Severe Features. Am J Perinatol 2017;34 (04):403-408. Doi: 10.1055/s-0036-1592134

11 Phoa KY, Chedraui P, Pérez-López FR, et al. Perinatal outcome in singleton pregnancies complicated with preeclampsia and eclampsia in Ecuador. J Obstet Gynaecol 2016;36(05):581-584. Doi: 10.3109/01443615.2015.1107532 